\title{
Fetal myelomeningocele repair: a narrative review of the history, current controversies and future directions
}

\author{
Kaeli J. Yamashiro, Diana L. Farmer \\ Department of Surgery, University of California-Davis, Sacramento, CA, USA \\ Contributions: (I) Conception and design: All authors; (II) Administrative support: None; (III) Provision of study materials or patients: None; (IV) \\ Collection and assembly of data: All authors; (V) Data analysis and interpretation: All authors; (VI) Manuscript writing: All authors; (VII) Final \\ approval of manuscript: All authors. \\ Correspondence to: Kaeli J. Yamashiro. Department of Surgery, University of California-Davis, 2335 Stockton Blvd, Room 5107, Sacramento, CA \\ 95817, USA. Email: kjyamashiro@ucdavis.edu.
}

\begin{abstract}
Fetal surgery is a relatively new field of medicine. The purpose of this narrative review is to present the history of how fetal surgery became the standard of care for myelomeningocele (MMC), the current controversies of this treatment, and active areas of research that may change how MMC is treated. Fetal surgery for MMC emerged out of the University of California, San Francisco in the 1980s in the laboratory of Dr. Michael Harrison. Initial research focused on testing the hypothesis that the in utero repair of MMC could improve outcomes in the ovine model. Evidence from this model suggested that in utero repair decreases the secondary damage to the exposed neural tissue and improves post-natal neurologic outcomes, opening the door for human intervention. This was followed by the Management of Myelomeningocele Study (MOMS), which was a multicenter randomized controlled trial comparing the prenatal versus postnatal MMC repair. The MOMS trial was stopped early due to the improved outcomes of the prenatal repair, establishing the open fetal MMC repair as the standard of care. Since the MOMS trial, two primary areas of controversy have arisen: the operative approach and criteria for the repair. The three operative approaches include open, endoscopic and a hybrid approach combining open and endoscopic. Several of the inclusion and exclusion criteria from the MOMS trial have been challenged, to include body mass index, gestational diabetes, other fetal abnormalities, maternal infections and Rh alloimmunization. New areas of research have also emerged, exploring cell based therapies to improve fetal outcomes, alternatives to fetal surgery and alternatives to primary skin closure of the fetus.
\end{abstract}

Keywords: Fetal myelomeningocele repair (fetal MMC repair); fetal surgery; myelomeningocele (MMC); repair technique

Submitted Mar 04, 2020. Accepted for publication Sep 24, 2020.

doi: $10.21037 / \mathrm{tp}-20-87$

View this article at: http://dx.doi.org/10.21037/tp-20-87

\section{Introduction}

Fetal surgery is an extraordinary field of medicine that emerged in the 1980s. With advancements in fetal diagnosis and therapy, myelomeningocele (MMC) became an indication for fetal repair for qualifying patients. The objective of this narrative review is to present the history of fetal surgery for MMC, followed by the outcomes, current controversies and active areas of research of the fetal MMC repair. We present the following article in accordance with the Narrative Review reporting checklist (available at http:// dx.doi.org/10.21037/tp-20-87).

\section{Methods}

A literature search was performed on PubMed and Google Scholar using the terms "history of fetal surgery", "fetal treatment of myelomeningocele", "management of 
myelomeningocele study" and "fetal myelomeningocele research". A search on ClinicalTrials.gov was also performed using the search term "myelomeningocele". Articles from the Management of Myelomeningocele Study (MOMS) were selected for the review of the history of the fetal MMC repair. Articles on the fetal MMC repair outside of the MOMS trial were selected to benchmark the MOMS trial outcomes. Articles published after the MOMS trial and differing from the standard established in the MOMS trial were selected as the current controversies. Articles after the MOMS trial that are researching novel methods for treatment of fetal MMC were selected for the review of the future direction of the fetal repair.

\section{Discussion}

\section{The bistory}

The field of fetal surgery emerged after ultrasonography allowed clinicians to evaluate the fetus in utero, a domain that was previously inaccessible. With this new technology, fetal anatomic abnormalities could now be diagnosed prenatally, raising the possibility of also intervening prenatally to improve clinical outcomes. When Dr. Harrison was a Resident caring for a neonate with a congenital diaphragmatic hernia (CDH), who later died due to the poor underlying pulmonary physiology, he, like many, wondered "...[if] the baby died because the lung was too small, and the lung was too small because it was not able to grow adequately before birth, ... [then] the only way to save the baby after birth [is] to fix the anatomic defect before birth" (1). After completing Residency and Fellowship training, Dr. Harrison joined Dr. Alfred De Lorimier at the University of California, San Francisco (UCSF), where Dr. De Lorimier had developed a fetal ovine model for CDH (2).

UCSF became the epicenter for fetal surgical research. The first experiments investigating fetal intervention were performed in the fetal ovine model evaluating the efficacy of the in utero treatment of $\mathrm{CDH}$, urinary tract obstructions and hydrocephalus in 1980 (1). However, the maternal safety of the in utero intervention could not be assessed in the ovine model, as the sheep uterus differs from the human uterus in that it is less susceptible to preterm labor with intervention (1). Thus, the maternal safety of a fetal intervention was subsequently evaluated in the most rigorous model possible, a non-human primate (macaque monkey) model in 1981 (1).

The first human in utero intervention was performed for a urinary tract obstruction at UCSF in 1982 . The success of this intervention propagated tremendous enthusiasm and media attention for this exciting new field, though there were concerns of quick adoption without first establishing the safety and efficacy of the intervention in humans, lack of ethical guidelines for intervention and a need for a collaborative nature in the field (1). This prompted an international meeting with leaders in the field to discuss these issues in 1982. From this meeting, it was agreed upon that fetal interventions would only be attempted for lethal diseases where the pathophysiology of the disease was understood and that interventions would be performed with strict adherence to ethical guidelines $(1,3)$. This meeting was called the International Fetal Medicine and Surgery Society (IFMSS) and continues to be held yearly.

As maternal safety of the fetal intervention improved, diseases that cause severe morbidity were then considered for fetal intervention. One of the non-lethal diseases investigated for fetal intervention was MMC. Dr. Michejda had the idea of prenatally repairing the MMC defect and began investigating potential fetal interventions in the early 1980s (4-6). Building on Dr. Michejda's idea, Drs. Martin and Claudia Meuli, two visiting research fellows from Switzerland, joined Drs. Harrison and N. Scott Adzick's research laboratory at UCSF and also began investigating the fetal repair of MMC. Dr. Maria Michejda observed that the neurologic damage from MMC appeared to be primarily from the secondary injury and destruction of the exposed neural tissue. They showed that the in utero repair could improve the neurologic function in the ovine model. These findings led to a fundamental change in the understanding of the pathogenesis of open spinal dysraphism, and were subsequently published in Nature Medicine (7). This finding was then confirmed in human fetuses with MMC (8). A second ovine MMC model, created by Dr. Diana Farmer and colleagues, demonstrated that the hindbrain herniation associated with the Arnold-Chiari II malformation could also be reversed with the fetal repair (9). With these translational breakthroughs of the potential benefits of the in utero repair, the first human fetal MMC repair was performed by Dr. Joseph Bruner at Vanderbilt University in $1997(1,10)$. This was followed by a rapid worldwide clinical expansion of human fetal surgery for the first non-lethal indication, MMC, without clear knowledge of the maternal and fetal risks and benefits. This led Dr. Farmer to propose a randomized controlled trial which ultimately led to the multi-center Management of Myelomeningocele Study (MOMS) (11). The trial was funded in 2002 by the National 
Table 1 Summary of the infant outcomes from the Management of Myelomeningocele Study (MOMS) at 12 months, 30 months and school-age (10-12,14-16)

\begin{tabular}{|c|c|c|c|c|c|c|}
\hline Variable & \multicolumn{2}{|c|}{12 months } & \multicolumn{2}{|c|}{30 months } & \multicolumn{2}{|c|}{ School-age } \\
\hline Arnold-Chiari II malformation & $64 \%$ & $96 \%$ & - & - & $61 \%$ & $87 \%$ \\
\hline VP shunt placed & $44.0 \%$ & $83.7 \%$ & - & - & $49 \%$ & $85 \%$ \\
\hline VP shunt revision & $15.4 \%$ & $40.2 \%$ & - & - & $23 \%$ & $60 \%$ \\
\hline Ambulation with orthotics or devices & - & - & $27.6 \%$ & $35.2 \%$ & $64 \%$ & $69 \%$ \\
\hline No ambulation & - & - & $27.6 \%$ & $40.9 \%$ & $7 \%$ & $20 \%$ \\
\hline$\geq 2$ level improvement in motor function compared to anatomic level & - & - & $26.4 \%$ & $11.4 \%$ & - & - \\
\hline 1 level improvement in motor function compared to anatomic level & - & - & $11.5 \%$ & $8 \%$ & - & - \\
\hline
\end{tabular}

Fetal = outcome from the fetal myelomeningocele repair, post = outcome from the postnatal myelomeningocele repair.

Institute of Health to rigorously compare the outcomes of the prenatal versus postnatal MMC repair (1). The MOMS trial was stopped early, after 8 years, by the Data Safety and Monitoring Board due to demonstrated efficacy of the prenatal repair. The MOMS trial, published in 2011 in the New England Fournal of Medicine, established the prenatal repair as the standard of care for select fetuses with MMC. This milestone article by Dr. Adzick et al. provoked a fundamental paradigm shift regarding the therapeutic approach towards one of the most devastating non-lethal malformations.

\section{The fetal MMC repair outcomes from the MOMS trial}

The outcomes from the MOMS trial are the standard by which all novel fetal MMC repairs are compared. The MOMS trial evaluated both maternal and fetal morbidity and mortality perinatally, at 12 months, 30 months and school-age (mean 7.8 years, range 5.9-10.3 years) (11-17). In the MOMS trial, the mean duration of the fetal surgery was 110.9 minutes and the mean duration of the uterine surgery was 64.8 minutes (11). The infant outcomes from the MOMS trial are summarized in Table 1.

In the MOMS trial, there was maternal morbidity from the fetal MMC repair, beyond the risk of having an operative procedure. This included an increased rate of preterm births $(81.3 \%)$, spontaneous membrane separation $(44.0 \%)$, spontaneous labor $(42.9 \%)$, chorioamniotic membrane separation (33.0\%), oligohydramnios (20.0\%), maternal transfusion at delivery $(8.8 \%)$ and placental abruption $(6.6 \%)$ (14). Dehiscence, either partial or complete, of the hysterotomy was noted in $11.4 \%$ of patients at the time of Cesarean delivery around 37 weeks of gestation (14). On further evaluation of the preterm births, $31.9 \%$ of the deliveries occurred between 35.0 and 36.6 weeks of gestation, $38.5 \%$ between 30.0 and 34.6 weeks of gestations and $11.0 \%$ at less than 30 weeks of gestation (14). Notably, the fetal MMC repair did not affect future fertility, though there was a higher rate of preterm deliveries in subsequent pregnancies compared to the postnatal repair group $(56.3 \%$ vs. $5.9 \%)(18)$.

For the fetus, the in utero repair decreased the frequency and severity of the Arnold-Chiari II malformation. At 12 months of age, hindbrain herniation was present in $64 \%$ of patients who underwent the fetal MMC repair, compared to $96 \%$ of patients who under the postnatal repair (11). Additionally, when present, the degree of hindbrain herniation was less, with $36 \%$ having no herniation, $40 \%$ having mild herniation, $19 \%$ having moderate herniation and only $6 \%$ having severe herniation (11). This benefit persisted at school-age, with $61 \%$ of prenatally repaired patients having hindbrain herniation, compared to $87 \%$ of the postnatal repair patients (12).

The fetal MMC repair also decreased ventriculoperitoneal shunt placements and revisions when compared to the postnatal MMC repair. When using the 
revised shunt placement criteria, by 12 months of age, $30.7 \%$ of the fetal MMC repairs met criteria and $44.0 \%$ received a shunt, compared to $71.7 \%$ of the postnatal surgery patients who met criteria and $83.7 \%$ who received a shunt (17). Of these patients, only $15.4 \%$ required a shunt revision by 1 year of age, compared to $40.2 \%$ of the postnatal surgery patients (17). On further analysis, prenatal ventricular size was a risk factor for meeting criteria for shunt placement in the fetal MMC group. Only $20 \%$ of patients with ventricles less than $10 \mathrm{~mm}$ required a shunt, whereas $89.5 \%$ of patients with ventricles of at least $15 \mathrm{~mm}$ required a shunt (17). This suggests that the benefit of decreasing shunt placement from the fetal MMC repair may be limited in fetuses with ventricles greater than $15 \mathrm{~mm}(17,19)$. Notably, the need for shunt placement did not affect the rate of independent ambulation, functional level of improvement or cognitive development at 30 months of age (13). The decreased need for shunt placements and revisions for the prenatally repaired MMC patients persisted at school-age, with $49 \%$ of patients requiring a shunt, compared to $85 \%$ of the postnatally repaired patients, and $23 \%$ needing shunt revision, compared to $60 \%$ of the postnatally repaired patients (12).

Motor function was also improved with the fetal MMC repair. When comparing the fetally repaired patients' functional motor level to the anatomic level of the lesion at 30 months of age, $11.5 \%$ had 1 level of improvement and 26.4\% had at least 2 levels of improvement, compared to $8.0 \%$ and $11.4 \%$ in the postnatal repair group, respectively (13). At 30 months of age, $44.8 \%$ of the fetally repaired patients walked independently, $27.6 \%$ required orthotics or devices to walk and $27.6 \%$ did not walk, compared to $23.9 \%, 35.2 \%$ and $40.9 \%$ in the postnatal surgery group, respectively (13). This comparative improvement persisted at school-age, with $29 \%$ of the fetally repaired patients walking independently, $64 \%$ ambulating with orthotics or an assistive device and only $7 \%$ unable to walk, compared to $11 \%, 39 \%$ and $20 \%$ in the postnatal surgery group respectively (12).

Additionally, there were improvements in the urologic outcomes with the fetal MMC repair at school-age. While there are limited short term improvements in urologic outcomes with no decrease in the need for clean intermittent catheterization (CIC) at 30 months of age, by school-age an improvement is demonstrated with $61.5 \%$ of the prenatal MMC repair patients required CIC, compared to $87.2 \%$ of the postnatally repaired patients $(15,16)$. Additionally, at school-age, there was an improvement in volitional voiding, occurring in $24.0 \%$ of prenatally repaired patients, compared to only $4.2 \%$ of postnatally repaired patients (16). There was also a decrease in post-void residual volume with the prenatal MMC repairs compared to the postnatal MMC repairs (16).

There is an increased need for tethered cord release with the fetal MMC repair compared to the postnatal repair. While there was no difference in the need for intervention at 12 months, at school-age, $27 \%$ of prenatally repaired patients required a tethered cord release compared to $15 \%$ of the postnatally repaired patients $(11,12)$.

\section{The fetal MMC repair outcomes outside of the MOMS trial}

Outcomes of the fetal MMC repair from prior to the MOMS trial, after the MOMS trial and European fetal surgery centers all provide additional data not reported in the MOMS trial and corroborate the results of the MOMS trial.

A 10-year follow-up of a single institution's cohort of patients who underwent the fetal MMC repair prior to the MOMS trial found that $88 \%$ of patients had some ability to ambulate, $74 \%$ of patients required CIC, 59\% were enrolled in a bowel management program and more children had impaired executive function when compared to children without MMC (20). Though these patients were older than those of the MOMS trial at the school-age follow up, the rate of ambulation is similar and the need for clean intermittent catherization is higher in this cohort compared to the MOMS trial. An additional evaluation of this same cohort demonstrated that $26 \%$ of the fetal surgery patients developed an epidermal inclusion cyst, of which, $71 \%$ were symptomatic (21). Patients with a cyst were at high risk of loss of bladder function and recurrence of either another inclusion cyst or tethered cord syndrome requiring surgical intervention (21). The development of inclusion cysts was not included in the outcomes the MOMS trial, however, data from the Zurich Center for Fetal Diagnosis and Therapy in Europe corroborate these findings (22).

Data from the fetal MMC repair performed after the MOMS trial are congruent with the outcomes of the MOMS trial. Both the Children's Hospital of Philadelphia and Vanderbilt University published case series of fetal repairs performed after the conclusion of the MOMS trial, with mostly similar outcomes as those observed in the MOMS trial (23-25). Additionally, at a fetal surgery center not involved in the MOMS trial, the gestational age at delivery and rate of hydrocephalus requiring shunting 
were similar to the MOMS trial (19). Importantly, the Zurich Center for Fetal Diagnosis and Therapy in Europe demonstrated comparable outcomes of the fetal MMC repair to the MOMS trial $(26,27)$. Finally, data from Poland demonstrated improved urinary function in patients who underwent the fetal MMC repair when compared to a postnatal repair, similar to the MOMS trial results (28). Taken together, these data indicate that the MOMS trial outcomes are reproducible worldwide outside of the rigors of a clinical trial.

\section{Current controversies of the fetal MMC repair}

There are two primary controversies with the fetal MMC repair. The first is the surgical approach (open versus fetoscopic), and the second are the inclusion and exclusion criteria for the fetal repair.

The surgical approaches for the fetal MMC repair are open, fetoscopic and a hybrid of the open and fetoscopic repairs (29). The open approach is performed through a maternal laparotomy followed by exteriorization of the uterus and a hysterotomy. The fetoscopic approach is performed by directly placing the fetoscopic ports through the maternal abdominal wall and uterus. The hybrid approach is performed through a maternal laparotomy followed by exteriorization of the uterus, similar to the open approach, however instead of performing a hysterotomy, fetoscopic ports are then placed through the uterus. Before the MOMS trial, both the open and fetoscopic approaches were utilized. However, during the MOMS trial, fetal MMC repairs were only being performed for patients enrolled in the trial and all of the repairs were performed with the open approach to ensure standardization of the intervention (13). Since the conclusion of the MOMS trial, the fetoscopic and hybrid approaches are being performed, in addition to the open approach. A metaanalysis comparing the various approaches demonstrates that the fetoscopic repair, compared to the open repair, requires increased revisions of the MMC site (28\% vs. $7 \%)$, and increased rate of preterm births (96\% vs. $81 \%)$ and increased premature rupture of membranes (91\% vs. 36\%), but decreased uterine dehiscence ( $0 \% v s .11 \%)(30)$. While the data on the fetoscopic repair are preliminary, there is concern of the comparability of the fetoscopic repair with the open repair. In one small study reporting on the outcomes of 10 patients who underwent a hybrid approach, there were some improved outcomes compared to the open approach, such as a decreased rate of preterm births $(10 \%$ vs. $81.3 \%$ ), decreased rate of Cesarean deliveries ( $40 \%$ vs. $100 \%)$, decreased uterine dehiscence ( $0 \%$ vs. $11.4 \%)$ and decreased surgery for tethered cord (0\% vs. 8\%) (31). There were similar rates of reversal of hindbrain herniation, functional level of improvement and mortality (31). However, the mean operative time was increased (246 vs. 110.9 minutes) and $10 \%$ of patients had a CSF leak at birth (31). While these data on the hybrid approach are promising, they are very preliminary and therefore may not be truly representative of the outcomes. The fetoscopic approaches tend to decrease maternal morbidity, however, the comparability of outcomes for the fetus and child are still undetermined.

The inclusion and exclusion criteria from the MOMS trial established the standard of care, though some of these criteria have been questioned. The MOMS trial inclusion criteria are: a singleton pregnancy, MMC lesion between $\mathrm{T} 1$ and S1 with hindbrain herniation, a gestational age of 19 weeks 0 days to 25 weeks 6 days, a normal karyotype and a maternal age of at least 18 years (11). The MOMS trial exclusion criteria are: maternal insulin-dependent pregestational diabetes, short or incompetent cervix or cervical cerclage, placenta previa or abruption, a body mass index (BMI) of $35 \mathrm{~kg} / \mathrm{m}^{2}$ or greater, a history of preterm birth, maternal HIV, Hepatitis-B or Hepatitis-C status positive, uterine anomaly, maternal condition that is a contraindication to surgery or general anesthesia, other fetal anomalies, kyphosis greater than 30 degrees, maternal-fetal $\mathrm{Rh}$ isoimmunization, Kell sensitization or a history of neonatal alloimmune thrombocytopenia, not meeting psychosocial criteria and maternal hypertension increasing the risk of preeclampsia or preterm delivery (11). Reported rates of ineligibility for the MMC repair due to the MOMS inclusion and exclusion criteria range from $34-56 \%(11,32,33)$. At the University of Texas at Houston, Dr. KuoJen Tsao is performing a clinical trial to evaluate the safety and efficacy of performing the fetal MMC repair with patients with one of the following exclusion criteria: BMI 35 to $45 \mathrm{~kg} / \mathrm{m}^{2}$, diabetes with good glycemic control, a history of a preterm birth as long as it was followed by a full term birth, a minor fetal structural abnormality that does not increase the risk of prematurity or maternal $\mathrm{Rh}$ alloimmunization (34). Other institutions are offering the fetal MMC repair to patients that have a BMI of up to $40 \mathrm{~kg} / \mathrm{m}^{2}$, with one institution reporting an earlier gestational age at delivery in these patients (35-38). Finally, Moehrlen et al. have reported performing a fetal MMC repair in a hepatitis-B positive mother, and the fetus 
remained hepatitis-B negative at a two year follow-up (39).

\section{Future direction of the fetal MMC repair}

There are many areas of active research aiming to improve the outcomes of the fetal MMC repair. These include cell based therapies, alternatives to fetal surgery and alternatives to the standard surgical repair of the fetal spinal cord lesion.

Dr. Dario Fauza and colleagues at Boston Children's Hospital are investigating transamniotic stem cell therapy (TRASCET) as an alternative to the open fetal MMC repair (40). They have investigated the use of mesenchymal stromal cells obtained from the amniotic fluid and the placenta (41). In various small animal models, TRASCET resulted in partial or complete skin coverage of the MMC defect with a decrease in the Arnold-Chiari II malformation (41-44). Further work is investigating the benefit of repeated injections and efficacy of the intervention in a large animal model $(40,43)$.

Dr. Diana Farmer and colleagues at the University of California, Davis are investigating augmenting the fetal MMC repair with early gestation placental mesenchymal stromal cells (PMSCs) to improve the neurologic outcomes. The PMSCs are applied to the MMC defect in utero at the time of the fetal repair $(45,46)$. Both in vitro and in vivo studies have demonstrated neuroprotective capabilities of the PMSCs resulting in a higher density of large motor neurons in the exposed spinal cord tissue $(47,48)$. In the ovine MMC model, the higher large motor neuron density correlates with a higher postnatal motor function, which rescues ambulation in the lambs who would otherwise have hindlimb paralysis (49-51). Criteria for selecting the PMSC cell line are established, IND enabling studies have been performed, FDA approval obtained, and a Phase I clinical trial is planned for January 2021 (46).

Dr. Ramesha Papanna and colleagues at the University of Texas at Houston are investigating the use of cryopreserved human umbilical cord as a skin patch for the fetal MMC repair when primary closure is not possible. Use of the human umbilical cord patch in the ovine MMC model showed regeneration of the epidermal, dermal and subcutaneous tissue layers, reversal of hindbrain herniation and preserved neurologic function $(52,53)$. The umbilical cord patch was subsequently used in two human cases. Both patients had an intact patch site with no CSF leakage, skin growth 3 to 4 weeks postnatally and reversal of hindbrain herniation (54).

Dr. Martin Meuli and colleagues in Switzerland are also investigating alternatives to primary fetal skin closure. In the ovine MMC model, they found that an autologous fetal skin graft transplanted in utero healed with a close to normal architecture (55). They are also investigating the use of human amniotic stem cells to generate keratinocytes that could be used to culture fetal epidermis for defect closure (56). Finally, they have shown that pedicled random pattern transposition flaps are helpful for skin defect coverage (57).

Dr. Alan Flake and colleagues at the Children's Hospital of Philadelphia are investigating the application of basic fibroblast growth factors (bFGFs) delivered on a gelatin scaffold as an alternative to primary closure of the fetal MMC repair (58). This intervention was evaluated in the rodent and ovine MMC model, and resulted in thicker overlying tissue, complete skin closure ranging in $0-100 \%$ of the animals depending on the composition of the delivery vehicle and animal model used and a thicker spinal cord when compared to no bFGFs $(58,59)$. Further areas of investigation include the efficacy of the bFGFs on neurologic function, scaffold engineering to ensure complete skin healing and the effects on tethered cord (58).

\section{Conclusions}

Taken together, experimental and clinical research efforts over the last 40 years have contributed to a great deal of pertinent improvements in diagnostic accuracy, operative management and outcomes for patients with MMC. This disorder has been transformed from one which was largely neglected, to one which now has a significant improvement with fetal treatment and is an active area of scientific investigation. Current research efforts hold promise that this devastating condition may be alleviated close to cure, so that someday all children with MMC may live disability free lives.

\section{Acknowledgments}

Funding: None.

\section{Footnote}

Provenance and Peer Review: This article was commissioned by the Guest Editors (Eric B. Jelin and George B. Mychaliska) for the series "Fetal Surgery" published in Translational Pediatrics. The article has undergone external peer review.

Reporting Checklist: The authors have completed the 
Narrative Review reporting checklist. Available at http:// dx.doi.org/10.21037/tp-20-87

Conflicts of Interest: Both authors have completed the ICMJE uniform disclosure form (available at http://dx.doi. org/10.21037/tp-20-87). The series "Fetal Surgery" was commissioned by the editorial office without any funding or sponsorship. DLF reports grants from California Institute for Regenerative Medicine, grants from Shriner's Hospital for Children, grants from National Institute of Health, outside the submitted work; in addition, DLF has a patent WO2016168752A1 licensed. The author has no other conflicts of interest to declare.

Ethical Statement: The authors are accountable for all aspects of the work in ensuring that questions related to the accuracy or integrity of any part of the work are appropriately investigated and resolved.

Open Access Statement: This is an Open Access article distributed in accordance with the Creative Commons Attribution-NonCommercial-NoDerivs 4.0 International License (CC BY-NC-ND 4.0), which permits the noncommercial replication and distribution of the article with the strict proviso that no changes or edits are made and the original work is properly cited (including links to both the formal publication through the relevant DOI and the license). See: https://creativecommons.org/licenses/by-nc-nd/4.0/.

\section{References}

1. Harrison MR. The University of California at San Francisco Fetal Treatment Center: a personal perspective. Fetal Diagn Ther 2004;19:513-24.

2. Adzick NS, Outwater KM, Harrison MR, et al. Correction of congenital diaphragmatic hernia in utero. IV. An early gestational fetal lamb model for pulmonary vascular morphometric analysis. J Pediatr Surg 1985;20:673-80.

3. Harrison MR, Filly RA, Golbus MS, et al. Fetal treatment 1982. N Engl J Med 1982;307:1651-2.

4. Michejda M, Bacher J, Kuwabara T, et al. In utero allogeneic bone transplantation in primates: roentgenographic and histological observations. Transplantation 1981;32:96-100.

5. Michejda M. Intrauterine treatment of spina bifida: primate model. Z Kinderchir 1984;39:259-61.

6. Michejda $M$. The fetal neural tube: is intervention progress? Z Kinderchir 1985;40 Suppl 1:53-7.
7. Meuli M, Meuli-Simmen C, Hutchins GM, et al. In utero surgery rescues neurological function at birth in sheep with spina bifida. Nat Med 1995;1:342-7.

8. Meuli M, Meuli-Simmen C, Hutchins GM, et al. The spinal cord lesion in human fetuses with myelomeningocele: implications for fetal surgery. J Pediatr Surg 1997;32:448-52.

9. Paek BW, Farmer DL, Wilkinson CC, et al. Hindbrain herniation develops in surgically created myelomeningocele but is absent after repair in fetal lambs. Am J Obstet Gynecol 2000;183:1119-23.

10. Bruner JP, Tulipan NE, Richards WO. Endoscopic coverage of fetal open myelomeningocele in utero. Am J Obstet Gynecol 1997;176:256-7.

11. Adzick NS, Thom EA, Spong CY, et al. A randomized trial of prenatal versus postnatal repair of myelomeningocele.

N Engl J Med 2011;364:993-1004.

12. Houtrow AJ, Thom EA, Fletcher JM, et al. Prenatal Repair of Myelomeningocele and School-age Functional Outcomes. Pediatrics 2020;145:e20191544.

13. Farmer DL, Thom EA, Brock JW, 3rd, et al. The Management of Myelomeningocele Study: full cohort 30-month pediatric outcomes. Am J Obstet Gynecol 2018;218:256.e1-e13.

14. Johnson MP, Bennett KA, Rand L, et al. The Management of Myelomeningocele Study: obstetrical outcomes and risk factors for obstetrical complications following prenatal surgery. Am J Obstet Gynecol 2016;215:778.e1-e9.

15. Brock JW 3rd, Carr MC, Adzick NS, et al. Bladder Function After Fetal Surgery for Myelomeningocele. Pediatrics 2015;136:e906-13.

16. Brock JW, 3rd, Thomas JC, Baskin LS, et al. Effect of Prenatal Repair of Myelomeningocele on Urological Outcomes at School Age. J Urol 2019;202:812-8.

17. Tulipan N, Wellons JC 3rd, Thom EA, et al. Prenatal surgery for myelomeningocele and the need for cerebrospinal fluid shunt placement. J Neurosurg Pediatr 2015;16:613-20.

18. Thom EA. 50: Maternal reproductive outcomes after inutero repair of myelomeningocele. American Journal of Obstetrics \& Gynecology 2016;214:S36.

19. Elbabaa SK, Gildehaus AM, Pierson MJ, et al. First 60 fetal in-utero myelomeningocele repairs at Saint Louis Fetal Care Institute in the post-MOMS trial era: hydrocephalus treatment outcomes (endoscopic third ventriculostomy versus ventriculo-peritoneal shunt). Childs Nerv Syst 2017;33:1157-68.

20. Danzer E, Thomas NH, Thomas A, et al. Long-term 
neurofunctional outcome, executive functioning, and behavioral adaptive skills following fetal myelomeningocele surgery. Am J Obstet Gynecol 2016;214:269.e1-e8.

21. Danzer E, Adzick NS, Rintoul NE, et al. Intradural inclusion cysts following in utero closure of myelomeningocele: clinical implications and follow-up findings. J Neurosurg Pediatr 2008;2:406-13.

22. Heye P, Moehrlen U, Mazzone L, et al. Inclusion Cysts after Fetal Spina Bifida Repair: A Third Hit? Fetal Diagn Ther 2019;46:38-44.

23. Moldenhauer JS, Adzick NS. Fetal surgery for myelomeningocele: After the Management of Myelomeningocele Study (MOMS). Semin Fetal Neonatal Med 2017;22:360-6.

24. Moldenhauer JS, Soni S, Rintoul NE, et al. Fetal myelomeningocele repair: the post-MOMS experience at the Children's Hospital of Philadelphia. Fetal Diagn Ther 2015;37:235-40.

25. Bennett KA, Carroll MA, Shannon CN, et al. Reducing perinatal complications and preterm delivery for patients undergoing in utero closure of fetal myelomeningocele: further modifications to the multidisciplinary surgical technique. J Neurosurg Pediatr 2014;14:108-14.

26. Möhrlen U, Ochsenbein-Kölble N, Mazzone L, et al. Benchmarking against the MOMS Trial: Zurich Results of Open Fetal Surgery for Spina Bifida. Fetal Diagn Ther 2020;47:91-7.

27. Horst M, Mazzone L, Schraner T, et al. Prenatal myelomeningocele repair: Do bladders better? Neurourol Urodyn 2017;36:1651-8.

28. Pastuszka A, Bohosiewicz J, Koszutski T. Prenatal myelomeningocele repair improves urinary continence and reduces the risk of constipation. Neurourol Urodyn 2018;37:2792-8.

29. Farmer DL, von Koch CS, Peacock WJ, et al. In utero repair of myelomeningocele: experimental pathophysiology, initial clinical experience, and outcomes. Arch Surg 2003;138:872-8.

30. Kabagambe SK, Jensen GW, Chen YJ, et al. Fetal Surgery for Myelomeningocele: A Systematic Review and MetaAnalysis of Outcomes in Fetoscopic versus Open Repair. Fetal Diagn Ther 2018;43:161-74.

31. Belfort MA, Whitehead WE, Shamshirsaz AA, et al. Fetoscopic Open Neural Tube Defect Repair: Development and Refinement of a Two-Port, Carbon Dioxide Insufflation Technique. Obstet Gynecol 2017;129:734-43.

32. AlRefai A, Drake J, Kulkarni AV, et al. Fetal myelomeningocele surgery: Only treating the tip of the iceberg. Prenat Diagn 2019;39:10-5.

33. Mazzone L, Moehrlen U, Casanova B, et al. Open Spina Bifida: Why Not Fetal Surgery? Fetal Diagn Ther 2019;45:430-4.

34. Extended Criteria For Fetal Myelomeningocele Repair. clinicaltrials.gov. 2016. Available online: https:// clinicaltrials.gov/ct2/show/NCT02664207. Accessed 2/13/20.

35. Open Myelomeningocele Repair with High Maternal BMI. ClinicalTrials.gov. 2017. Available online: https:// clinicaltrials.gov/ct2/show/NCT03044821. Accessed 02/13/20.

36. Fetal Surgery Guidelines for Prenatal Myelomeningocele Repair. Children's Hospital of Philadelphia. Available online: https://www.chop.edu/pages/fetal-surgeryguidelines-prenatal-myelomeningocele-repair. Accessed 2/13/20.

37. Pan ET, Pallapati J, Krueger A, et al. Evaluation and Disposition of Fetal Myelomeningocele Repair Candidates: A Large Referral Center Experience. Fetal Diagn Ther 2020;47:115-22.

38. Hilton SA, Hodges MM, Dewberry LC, et al. MOMS Plus: Single-Institution Review of Outcomes for Extended BMI Criteria for Open Fetal Repair of Myelomeningocele. Fetal Diagn Ther 2019;46:411-4.

39. Moehrlen U, Elrod J, Ochsenbein-Kölble N, et al. In utero Hepatitis B Immunization during Fetal Surgery for Spina Bifida. Fetal Diagn Ther 2020;47:328-32.

40. Lazow SP, Fauza DO. Transamniotic Stem Cell Therapy. Adv Exp Med Biol 2020;1237:61-74.

41. Feng C, D Graham C, Connors JP, et al. A comparison between placental and amniotic mesenchymal stem cells for transamniotic stem cell therapy (TRASCET) in experimental spina bifida. J Pediatr Surg 2016;51:1010-3.

42. Dionigi B, Ahmed A, Brazzo J 3rd, et al. Partial or complete coverage of experimental spina bifida by simple intra-amniotic injection of concentrated amniotic mesenchymal stem cells. J Pediatr Surg 2015;50:69-73.

43. Shieh HF, Tracy SA, Hong CR, et al. Transamniotic stem cell therapy (TRASCET) in a rabbit model of spina bifida. J Pediatr Surg 2019;54:293-6.

44. Dionigi B, Brazzo JA 3rd, Ahmed A, et al. Trans-amniotic stem cell therapy (TRASCET) minimizes Chiari-II malformation in experimental spina bifida. J Pediatr Surg 2015;50:1037-41.

45. Lankford L, Chen YJ, Saenz Z, et al. Manufacture and preparation of human placenta-derived mesenchymal 
stromal cells for local tissue delivery. Cytotherapy 2017;19:680-8.

46. Galganski LA, Kumar P, Vanover MA, et al. In Utero Treatment of Myelomeningocele with Placental Mesenchymal Stromal Cells - Selection of an Optimal Cell Line in Preparation for Clinical Trials. J Pediatr Surg 2020;55:1941-6.

47. Brown EG, Keller BA, Lankford L, et al. Age Does Matter: A Pilot Comparison of Placenta-Derived Stromal Cells for in utero Repair of Myelomeningocele Using a Lamb Model. Fetal Diagn Ther 2016;39:179-85.

48. Chen YJ, Chung K, Pivetti C, et al. Fetal surgical repair with placenta-derived mesenchymal stromal cell engineered patch in a rodent model of myelomeningocele. J Pediatr Surg 2017. [Epub ahead of print].

49. Wang A, Brown EG, Lankford L, et al. Placental mesenchymal stromal cells rescue ambulation in ovine myelomeningocele. Stem Cells Transl Med 2015;4:659-69.

50. Vanover M, Pivetti C, Lankford L, et al. High density placental mesenchymal stromal cells provide neuronal preservation and improve motor function following in utero treatment of ovine myelomeningocele. J Pediatr Surg 2019;54:75-9.

51. Kabagambe S, Keller B, Becker J, et al. Placental mesenchymal stromal cells seeded on clinical grade extracellular matrix improve ambulation in ovine myelomeningocele. J Pediatr Surg 2017. [Epub ahead of print].

52. Papanna R, Moise KJ Jr, Mann LK, et al. Cryopreserved human umbilical cord patch for in-utero spina bifida

Cite this article as: Yamashiro KJ, Farmer DL. Fetal myelomeningocele repair: a narrative review of the history, current controversies and future directions. Transl Pediatr 2021;10(5):1497-1505. doi: 10.21037/tp-20-87 repair. Ultrasound Obstet Gynecol 2016;47:168-76.

53. Papanna R, Mann LK, Snowise S, et al. Neurological Outcomes after Human Umbilical Cord Patch for In Utero Spina Bifida Repair in a Sheep Model. AJP Rep 2016;6:e309-17.

54. Papanna R, Fletcher S, Moise KJ Jr, et al. Cryopreserved Human Umbilical Cord for In Utero Myeloschisis Repair. Obstet Gynecol 2016;128:325-30.

55. Mazzone L, Moehrlen U, Ochsenbein-Kolble N, et al. Bioengineering and in utero transplantation of fetal skin in the sheep model: A crucial step towards clinical application in human fetal spina bifida repair. J Tissue Eng Regen Med 2020;14:58-65.

56. Basler M, Pontiggia L, Biedermann T, et al. Bioengineering of Fetal Skin: Differentiation of Amniotic Fluid Stem Cells into Keratinocytes. Fetal Diagn Ther 2020;47:198-204.

57. Meuli M, Meuli-Simmen C, Mazzone L, et al. In utero Plastic Surgery in Zurich: Successful Use of Distally Pedicled Random Pattern Transposition Flaps for Definitive Skin Closure during Open Fetal Spina Bifida Repair. Fetal Diagn Ther 2018;44:173-8.

58. Watanabe M, Li H, Kim AG, et al. Complete tissue coverage achieved by scaffold-based tissue engineering in the fetal sheep model of Myelomeningocele. Biomaterials 2016;76:133-43.

59. Watanabe M, Jo J, Radu A, et al. A tissue engineering approach for prenatal closure of myelomeningocele with gelatin sponges incorporating basic fibroblast growth factor. Tissue Eng Part A 2010;16:1645-55. 